\title{
Involving Older Adults in Developing Physical Activity Interventions to Promote Engagement: a Literature Review
}

\author{
Elisabeth R Boulton $^{1,2}$ (D) Maria Horne ${ }^{3} \cdot$ Chris Todd $^{1,2,4}$ \\ Received: 14 March 2018 / Accepted: 26 May 2019 / Published online: 24 June 2019 \\ (C) The Author(s) 2019
}

\begin{abstract}
Physical activity (PA) is associated with health benefits, with policy across the world focussing on increasing participation. Yet uptake and adherence to PA amongst older adults remains below the recommended $150 \mathrm{~min} /$ week. This review aims to identify how older adults have been involved in the design, delivery, implementation and promotion of interventions to promote PA uptake and adherence, and whether there are any recorded benefits of this involvement. Systematic searches of CINAHL, Embase, HMIC, MEDLINE, PsychINFO, Social Policy and Practice and the SSCI were undertaken. Inclusion/exclusion criteria were: (i) Original research; (ii) older adults, 50+; (iii) community dwelling; (iv) involvement in design, delivery, implementation or promotion of interventions. A narrative synthesis of ten studies is presented, following systematic methods, reporting study design and intervention type; participants and context; nature of involvement; effectiveness of interventions. Six different types of involvement were evident: (i) consultation; (ii) cooperation; (iii) co-learning; (iv) collaboration; (v) peer leadership and (vi) mentoring. Levels of success were reported, yet specific factors were difficult to isolate. The studies reported complex interventions which were reported as successful. However, it is difficult to state whether success was a result of the older adults' involvement, as the benefits of involving older adults were not tracked or reported. Future research should be clear about the nature of involvement, the context in which research takes place, and the description of action and outcomes. Policy makers should consider the advantages to be gained from involving older adults in intervention development.
\end{abstract}

Keywords Physical activity · Older adults · Engagement · User involvement

Elisabeth R Boulton

elisabeth.boulton@manchester.ac.uk

Extended author information available on the last page of the article 


\section{Introduction}

Generally physical activity (PA) is associated with health benefits. Higher levels and greater frequency of PA have been associated with lower risk of chronic disease and long term conditions (Cavill et al. 2006; Department of Health 2004; Sport England 2007). Regular PA is associated with improvements in mental health and wellbeing, self-esteem, stress reduction and depression (Department of Health 2005; Department of Health 2009; Falkingham et al. 2010). Levels of cognitive function can be improved (Angevaren et al. 2008) and the risk of dementia reduced (Chief Medical Officers 2011). Yet uptake of and adherence to PA amongst older adults remains below the recommended 150 min per week (Chief Medical Officers 2011; World Health Organization 2010).

Worldwide, policy has focused on encouraging the population to engage in PA to improve health (Centers for Disease Control and Prevention 2015; Health Direct Australia 2016; Ministry of Health 2013). Recent policy initiatives provide guidance to the older population and to those working with older adults on how to incorporate increased amounts of PA into everyday life (NHS Choices 2015; World Health Organization 2015).

Programmes promoting PA amongst older adults have demonstrated increased levels of PA amongst participants (CLES Consulting and the New Economics Foundation 2010; Stewart et al. 2001). For example, the Community Healthy Activities Model Program For Seniors, CHAMPS II (USA) and Fit as a Fiddle (UK). Many initiatives have focused on prescribing PA for older adults with long-term conditions and research has looked at the effectiveness of advice from primary care practitioners and of formal exercise referral schemes (Hillsdon et al. 2002; Horne et al. 2010; Morgan 2005). However, these schemes are aimed at people who have already presented with a health issue. They are not primary prevention strategies and do not lead to sustained PA adherence (Horne et al. 2010; Morgan 2005).

The benefits of involving people in improving their own health and wellbeing have been recognised in UK policy development (Department of Health 2010; Department of Health 2012; NHS England 2013). Participatory approaches to achieve better health outcomes are used in the fields of chronic conditions management, healthy eating and reducing 'risky' behaviours such as smoking and illicit drug use (Hibbard and Greene 2013; Minkler et al. 2008). Participatory approaches recognise that people and communities should be the focus of health and social care systems and can, and should, have a powerful role identifying need and the development of strategies and services (Department of Health 2012). This approach is congruent with participatory research methodologies, such as action research, which recognise the value of 'users' in the research process. In participatory research, action is taken to address problematic situations, through collaboration between people affected by the problem (Herr and Anderson 2005). There may be generation of knowledge and theory, but there is always a focus on action and on change, together with an underlying belief that people are more receptive to change if they are involved in decision making (Waterman et al. 2001). Engaging patients as peer leaders or peer supporters has led to better outcomes in terms of self-management of diabetes (Lorig and Alvarez 2011) and general management of chronic conditions (Frosch et al. 2010). Likewise, participatory decision 
making with service providers led to increases in medication adherence, levels of engagement in self-management and improved health status (Parchman et al. 2010) .

There are, then, indications that the involvement of older adults in the design, development, implementation and promotion of interventions to promote physical activity amongst their age group could contribute towards better outcomes. From theoretical and psychological standpoints, involving the target population in developing interventions makes sense, since it can generate ownership and focus on what is important to those communities (Minkler et al. 2008; Ramsden et al. 2010). As such, the aims of this review are twofold: (i) to identify the extent to which older adults have been involved in the design, delivery, implementation and promotion of primary prevention interventions to promote PA uptake and adherence amongst their age group, and (ii) to identify any recorded benefit of involving older adults in this way.

\section{Methods}

Established standards for systematic reviews were followed (Centre for Reviews and Dissemination 2008) and data were extracted and synthesised adopting the principles of realist review (Pawson et al. 2005). Whilst systematic reviews are regarded as the gold standard for synthesising evidence from simple interventions, especially randomised controlled trials, (Centre for Reviews and Dissemination 2008), when dealing with heterogeneity and complex interventions, realist reviews can provide detailed understandings of complex social interventions, where the context of the research plays a key role in its implementation, successful or otherwise (Pawson et al. 2005). Although this review is not a formal realist review, it has been influenced by the principles of realist review. According to Pawson et al. (2005) traditional systematic review methods focus on programme effectiveness and do not provide insight into why interventions work, or not, in different circumstances. In contrast, realist review undertakes "explanatory analysis aimed at discerning what works for whom, in what circumstances, in what respects and how" p21. The hallmark of the realist approach is a clear understanding of causality: it is essential to understand the underlying mechanism that connects different events, together with the context in which they occur, in order to infer a causal outcome. For example, to understand whether a complex intervention to increase PA (including a media campaign and PA guidance) has led to more physically active population, a realist would need to understand the mechanisms (e.g. have PA levels increased?) and the context (e.g. what else was going on in that community that may have influenced PA behaviour?) (Pawson et al. 2005).

Therefore, this review addresses the study designs, context, nature of involvement and recorded benefits of involving older adults in the design, delivery, implementation and promotion of primary prevention interventions to promote PA uptake and adherence amongst their age group.

\section{Search Strategy}

Systematic searches were undertaken using CINAHL, Embase, HMIC, MEDLINE, PsychINFO, Social Policy and Practice and the Social Sciences Citation Index and are up to date in January 2019. No date restrictions were applied. Papers were restricted to 
English. Terms searched included those relating to older adults; involvement, design, delivery, implementation and promotion; participation, membership or attendance; community groups, activities and interventions; PA and exercise. All study designs were included. Additional articles were identified through searching the references of included articles. One researcher (EB) led the review process with guidance and support from two experienced researchers (CT and $\mathrm{MH}$ ). Search terms, searches and the identified papers were reviewed and considered by all authors.

\section{Inclusion / Exclusion Criteria}

Papers meeting the following criteria were reviewed: (i) original research; (ii) included older adults; (iii) participants, or the population under study, must be community dwelling; and (iv) older adults must be involved at some level in the design, delivery, implementation or promotion of an intervention promoting PA. Studies where older adults were participants only, playing no reported part in study design, were excluded (see PRISMA diagram Fig. 1). The search terms and strategy used in Ovid are included in Table 1. For the purpose of this review, the term 'older adults' is not associated with any particular age group, or cut off point. The definition has been kept as broad as possible, to capture a wide range of interventions.

\section{Data Extraction and Quality Assessment}

Various quantitative, mixed methods, participatory, action research, case study and exploratory studies were identified for inclusion in this review and are summarised in the data extraction tables (see supporting material available through the online edition). No exclusively qualitative studies were identified.

Due to diversity in study designs, the papers were quality assessed using five separate tools to cover appraisal issues for different research methodologies as suggested in Waterman et al.'s systematic review and guidance for action research reports (Waterman et al. 2001); the Quality Assessment Tool for Quantitative Studies by the Effective Public Health Practice Project (Effective Public Health Practice Project 2007); the STROBE Statement checklist of items to be included in reporting observational studies (Von Elm et al. 2008); the Health Technology Assessment checklist for assessing the quality of quantitative studies (Kmet et al. 2004); a modified version of the Scottish Intercollegiate Guidelines Network evidence based guidelines (SIGN 2008). Papers were scored against the relevant criteria and the quality assessments were agreed by all three authors. Papers rated as moderate or better quality were included in the review. A quality assessment ratings summary is included in Table 2, showing which tools were used for each of the included papers.

\section{Data Synthesis}

Quantitative data are largely descriptive, therefore a narrative synthesis has been adopted, following the core principles and methods for conducting systematic 


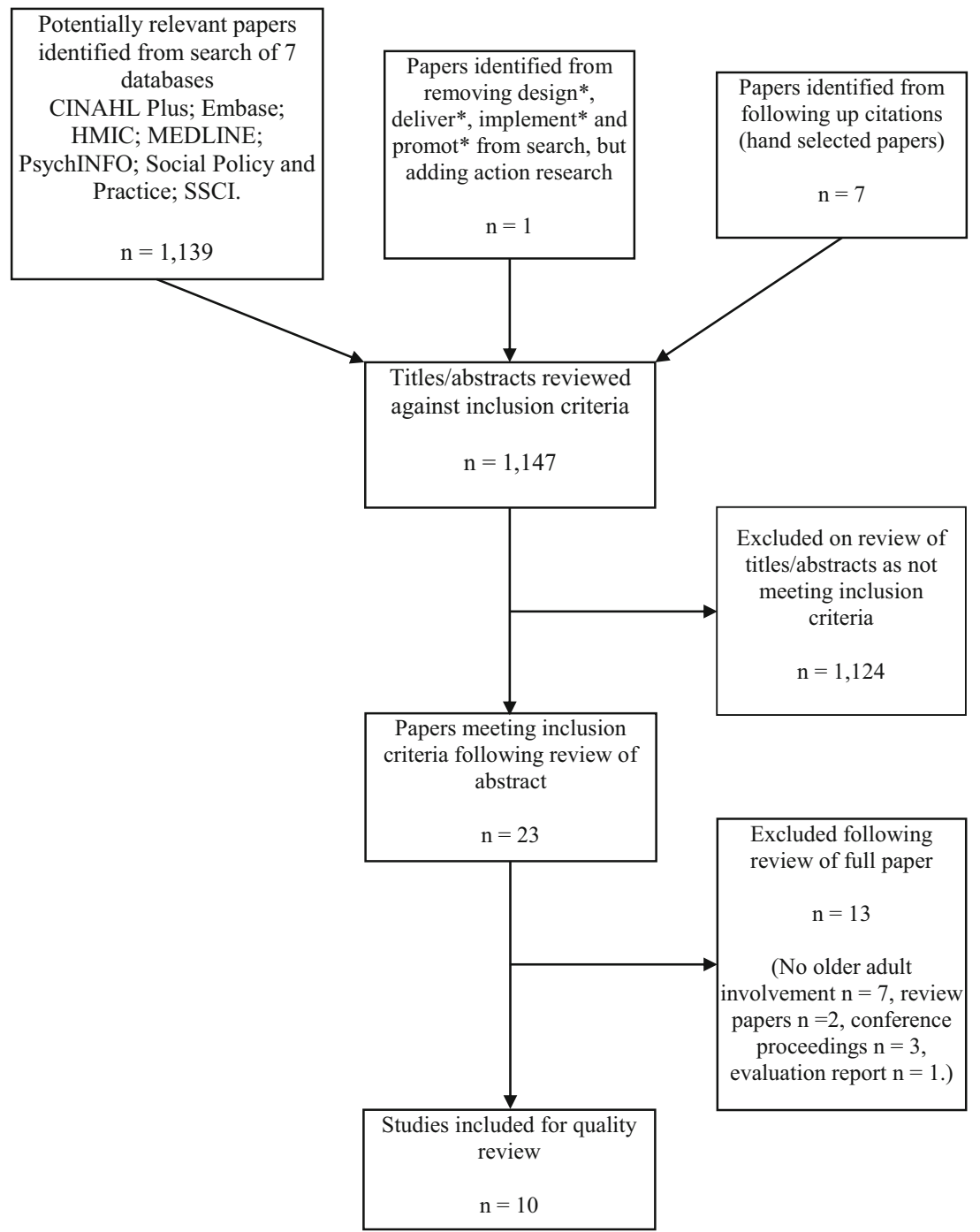

Fig. 1 PRISMA Diagram: studies included and excluded in review

reviews developed by the Centre for Reviews and Dissemination (Centre for Reviews and Dissemination 2008).

Data on the study design and context, the participants involved, the nature of older adults' involvement, and the interventions' effects were extracted and synthesised. The nature of older adults' involvement in the studies is reported. The types of involvement were categorised according to the different levels of participation described in Waterman et al. (2001) and Minkler and Wallerstein (2008): (i) consultation, where older adults' opinions were sought about increasing PA; (ii) cooperation, where local people worked together with outsiders to determine priorities for increasing PA; (iii) colearning, where local people and outsiders shared their knowledge and worked together to form action plans to increase PA; and (iv) collaboration, where local people set the 
Table 1 Search terms and strategy used in Ovid (MEDLINE, Embase, PsychINFO, HMIC, and Social Policy and Practice)

1. older people

2. older adult*

3. senior*

4. elder*

5. ag?ing

6. senior citizen*

7. Combined 1-6 with OR

8. involve*

9. engage*

10. consult*

11. user involvement

12. Combine 8-11 with OR

13. design*

14. deliver*

15. implement*

16. promot*

17. Combine 13-16 with $O R$

18. attend*

19. join*

20. member*

21. participat*

22. Combine 18-21 with OR

23. community groups

24. activit*

25. session*

26. class*

27. scheme*

28. intervention*

29. Combine 23-28 with OR

30. Combine 7, 12, 17, 22, 29 with AND

31. physical activit*

32. exercise

33. 31 OR 32

34. 30 AND 33

35. Limit to English Language

agenda and lead the action. Where it was more difficult to categorise the level of involvement using these descriptors, the categories of peer leadership and mentoring were added. These latter two categories were drawn from the included studies and were defined following Simoni et al. (2011), and Peel and Warburton (2009), two studies examining the effectiveness of harnessing peer support in health promotion. 
Table 2 Summary of quality assessment ratings for included studies

\begin{tabular}{|c|c|c|}
\hline Authors & Study design & Quality rating [Tool] \\
\hline Buman et al. 2013 & Participatory & Moderate a,b \\
\hline Davies et al. 2008 & Participatory & Moderate a,b \\
\hline Hickey et al. 1996 & Participatory & Moderate $\mathrm{a}, \mathrm{b}$ \\
\hline Buman et al. 2011 & RCT & Strong $\mathrm{c}$ \\
\hline Hooker et al. 2011 & Cohort: quasi experimental pre-post & Strong $\mathrm{c}$ \\
\hline Li et al. 2008 & Mixed Methods & Moderate \\
\hline Michael et al. 2012 & Case report & Good $+^{\mathrm{d}}$ \\
\hline Reger-Nash et al. 2003 & Cohort: 2 community longitudinal & Good $++^{d}$ \\
\hline Ståhl et al. 2008 & Mixed Methods & Good $++^{d}$ \\
\hline Sullivan-Marx et al. 2011 & Exploratory & Good $+{ }^{\mathrm{d}}$ \\
\hline
\end{tabular}

\footnotetext{
a Popay et al. 1998

b Waterman et al. 2001

c Effective Public Health Practice Project 2007

d Scottish Intercollegiate Guidelines Network 2008
}

\section{Results}

The study selection process is illustrated in Fig. 1. Initially we identified 1147 papers and the titles and abstracts were reviewed against the inclusion/exclusion criteria. Twenty-three papers remained to be considered in full (Fig. 1). Thirteen papers were excluded following a review of the full paper (seven with no older adult involvement; two review papers, three conference proceedings; one evaluation report). Ten papers were included in the review.

\section{Objective One: Extent of Involvement in Interventions}

\section{Study Designs, Interventions and Quality Assessments}

Details of the included studies' designs, interventions and quality assessments are presented in Tables 2 and 3. Three participatory studies, including one action research study, were identified. Buman et al. (2013) report on the development of a tool enabling older adults to identify barriers to active living in their neighbourhood. Davies et al. (2008) describe an action research study developed to establish a sustainable exercise class in a small, semi-rural town. Hickey et al. (1996) report on the establishment of a sustainable exercise class, through development of peer leadership, within a senior centre environment.

One randomised controlled trial (RCT) was identified: Buman et al. (2011) investigated the effectiveness of peer mentoring during a 16-week trial to encourage older adults to be more physically active, through delivering sessions based on socialcognitive and self-determination theories. One quasi-experimental study (Hooker et al. 2011), reported the effect of incorporating rigorous formative research findings in an intervention to promote PA amongst a group of African American older men. 


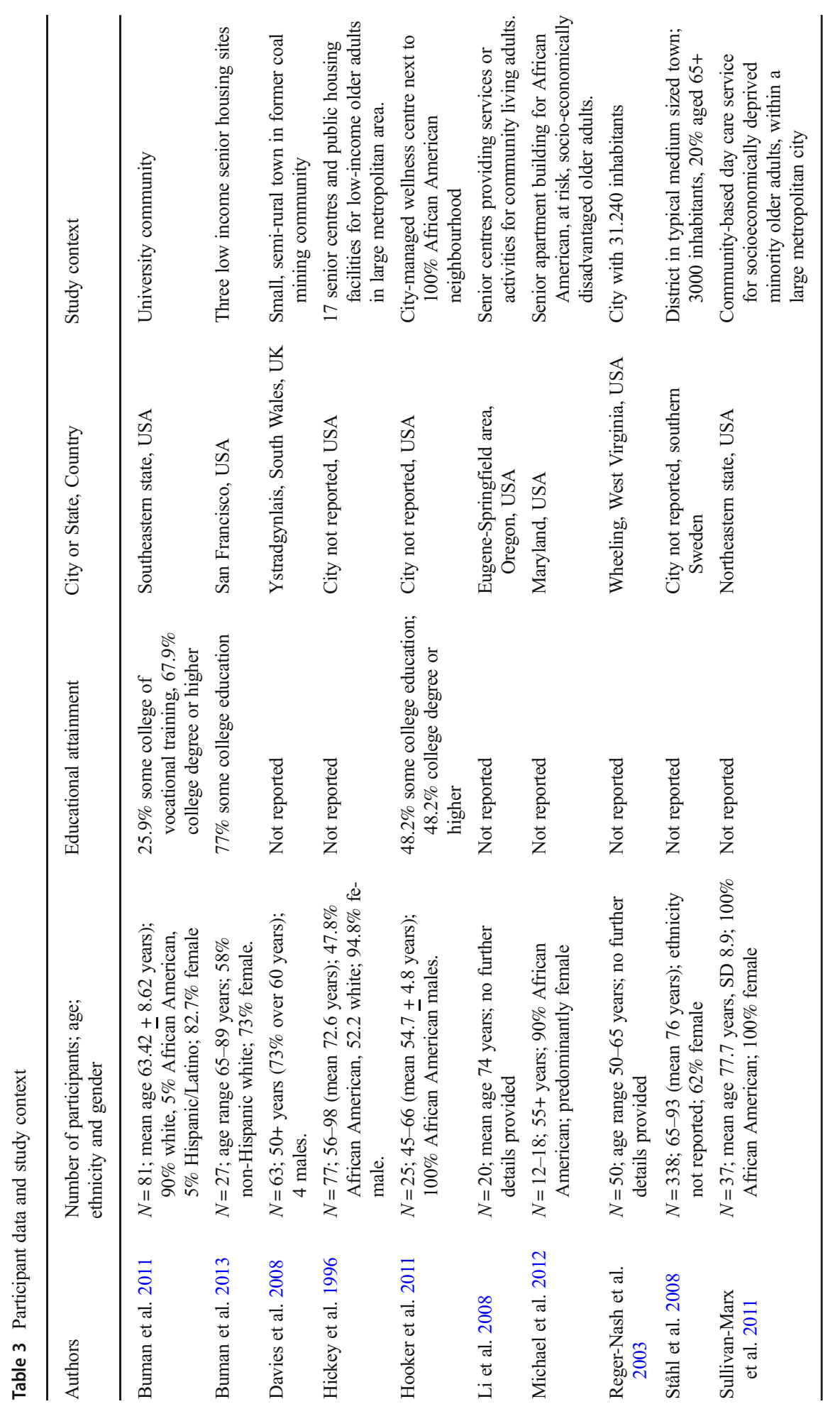


Reger-Nash et al. (2003) present a cohort study with a two-community longitudinal design. This study aimed to motivate older adults to be more physically active through promoting walking for $30 \mathrm{~min}$ each day.

Two mixed methods studies are included. Li et al. (2008) report an evaluation of the iterative development of an evidence-based, community-based Tai Chi programme, including feasibility and pilot testing. Ståhl et al. (2008) describe a three-phase exploratory quantitative - qualitative sequential study, identifying barriers and facilitators to active living within the local outdoor environment.

One case report is included, by Michael et al. (2012), which reports on the phase of research following a cohort study with a single group, repeated measures design. The on-going research presented describes the development and influence of peer leadership at an exercise class, which followed a12-week pilot intervention. The final study included, by Sullivan-Marx et al. (2011), is observational and exploratory, describing the effect of implementing particular recruitment and retention strategies for an exercise class in a senior centre.

\section{Participants and Context}

Whilst all the studies included in the review focused on older adults, their location and context differed. Details of participants' sociodemographic data and context are provided in Table 3. Participants in the studies reviewed were drawn from communities with very different socio-demographic compositions; mostly in the USA but including one UK and one Swedish study (Table 3). The included studies thus present a variety of different contexts and study populations with different sociodemographic characteristics, which will have affected the interventions' effectiveness.

\section{Nature of Involvement}

The nature of older adults' involvement in the included studies varied between and within studies. Consultation, co-operation, co-learning and collaboration were all evident, and peer leadership or mentoring were described in four studies. The types of involvement in the included studies are summarised in Table 4. Short descriptions of each of these types of involvement are provided, following the definitions in Waterman et al. (2001); Minkler and Wallerstein (2008); Simoni et al. 2011; and Peel and Warburton (2009). Below we address each type of involvement in turn, preceded by a definition of the term.

Consultation Defined as seeking the opinions of local people to inform plans and decision making. Analysis and decisions are undertaken by researchers who are 'outsiders' (Waterman et al. 2001).

Hooker et al. (2011) report on an intervention based on formative research with the target population (Burroughs et al. 2009, 2009a) demonstrating how those findings were tested. The consultation had led to a focus on responsibility and traditional views of masculine identity for African American men, and also on social interaction and friendly competition. Two trained workers delivered the eight-week intervention of twice-weekly group sessions with participants' progress against goals being reported and measured against others' progress. The sessions were made accessible through 
Table 4 Types of involvement and related studies

\begin{tabular}{|c|c|c|}
\hline $\begin{array}{l}\text { Type of } \\
\text { involvement }\end{array}$ & Intervention & Authors \\
\hline Consultation & $\begin{array}{l}\text { The Stanford Healthy Neighborhood } \\
\text { Discovery Tool } \\
\text { Triangle Ystradgynlais Fitness 50+ project } \\
\text { Unnamed pilot programme } \\
\text { Tai Chi: Moving for Better Balance } \\
\text { Wheeling Walks } \\
\text { "Let's go for a walk! }\end{array}$ & $\begin{array}{l}\text { Buman et al. } 2013 \\
\text { Davies et al. } 2008 \\
\text { Hooker et al. } 2011 \\
\text { Li et al. } 2008 \\
\text { Reger-Nash et al. } 2003 \\
\text { Ståhl et al. } 2008\end{array}$ \\
\hline Cooperation & $\begin{array}{l}\text { The Stanford Healthy Neighborhood Discovery Tool } \\
\text { SMILE (So Much Improvement with a Little } \\
\text { Exercise) programme } \\
\text { Wheeling Walks } \\
\text { "Let's go for a walk!" }\end{array}$ & $\begin{array}{l}\text { Buman et al. } 2013 \\
\text { Hickey et al. } 1996 \\
\text { Reger-Nash et al. } 2003 \\
\text { Ståhl et al. } 2008\end{array}$ \\
\hline Co-learning & $\begin{array}{l}\text { The Stanford Healthy Neighborhood Discovery Tool } \\
\text { Triangle Ystradgynlais Fitness 50+ project } \\
\text { SMILE (So Much Improvement with a Little Exercise) } \\
\quad \text { programme } \\
\text { Wheeling Walks }\end{array}$ & $\begin{array}{l}\text { Buman et al. } 2013 \\
\text { Davies et al. } 2008 \\
\text { Hickey et al. } 1996 \\
\text { Reger-Nash et al. } 2003\end{array}$ \\
\hline Collaboration & $\begin{array}{l}\text { "Let's go for a walk!" } \\
\text { "Exercise of LIFE" }\end{array}$ & $\begin{array}{l}\text { Ståhl et al. } 2008 \\
\text { Sullivan-Marx et al. } 2011\end{array}$ \\
\hline Peer leadership & $\begin{array}{l}\text { Triangle Ystradgynlais Fitness } 50+\text { project } \\
\text { SMILE (So Much Improvement with a } \\
\text { Little Exercise) programme } \\
\text { PRAISEDD project }\end{array}$ & $\begin{array}{l}\text { Davies et al. } 2008 \\
\text { Hickey et al. } 1996 \\
\text { Michael et al. } 2012\end{array}$ \\
\hline Mentoring & Active Adult Mentoring Program & Buman et al. 2011 \\
\hline
\end{tabular}

situating them in a local centre next to a neighbourhood with a $100 \%$ African American population. Finally, a sense of identification and ownership of the programme was generated through team membership, organised group activities and provision of a programme branded t-shirt.

Two other studies concerned older adults being consulted on the development of community exercise classes or programmes. Older adults were involved at three different stages of the 'Tai Chi: Moving for Better Balance' programme (Li et al. 2008). 1) Reviewing the Tai Chi class's videotape and guidebook for usability and acceptability. 2) A survey of 81 older adults attending existing activity classes. 3) A satisfaction survey of 20 older adults attending a twoweek, twice-weekly pilot Tai Chi class. In the study reporting on the 'Triangle Ystradgynlais Fitness 50+' project (Davies et al. 2008), the need for a daytime community exercise class for people 50 years of age and older was identified through community consultation.

Consultation formed part of the development of the 'Stanford Healthy Neighborhood Tool' (Buman et al. 2013) and 'Let's got for a walk!' (Ståhl et al. 2008). In both studies, the tools were developed following consultations with older adults. In the latter study, the consultation phase involved the administration of a semistructured postal questionnaire for residents aged 65 and older regarding their travel habits, accessibility and safety issues in the district. 
Co-Operation Local people and 'outsiders' working together to agree priorities for action and change. The responsibility for leading the process sits with the 'outsiders' (Waterman et al. 2001).

In the 'SMILE' programme (Hickey et al. 1996)' older adults attending the centres co-operated with researchers through providing advice on the design and promotion of a sustainable programme. They developed two clear objectives: 1) focus on the exercises' health benefits; 2) involve participants as peer leaders. A small group of older adults helped recruit participants for exercise sessions, providing advice on scheduling, overcoming obstacles to participation and making suggestions for making the sessions appealing.

The 'Wheeling Walks' study (Reger-Nash et al. 2003) began with Community Health Participatory Planning, ensuring that older community members were involved in the message development for the media-based walking campaign. Older community members worked with the research team, leaders of local organisations, local stakeholders, representatives from minority populations and government officials to develop effective, targeted messages encouraging people aged between 50 and 65 to walk more. During the eight-week intensive media campaign, the Wheeling Walks Community Advisory Board, which included older adults, met regularly and participated in campaign events. Board members were surveyed before and after the campaign about empowerment and their ability to effect community change. Though cooperation was the dominant form of involvement in this study, consultation and co-learning were also evident.

In two studies, older adults were instrumental in collecting data for developing interventions. Both studies identified factors that influence the accessibility of local neighbourhoods for older adults. Buman et al. (2013) describe the development of a computerised environmental assessment tool ('The Stanford Healthy Neighborhood Tool') capturing audio recordings and photographs. Some 27 residents undertook walks around their local neighbourhoods, recording barriers and facilitators to being active in those areas. The tool they used had been developed following consultation and pilot testing by six residents of the same sites. Following the data collecting walks, a data review was carried out with residents and a post-assessment survey was conducted. Residents' feedback led to further work on the computerised tool. Again, co-operation was the primary type of involvement, with consultation and co-learning both in evidence. 'Let's go for a walk!' (Ståhl et al. 2008) included co-operation in the form of participant observations undertaken by a purposive sample of 10 residents. These observations involved an accompanied walk reporting problems encountered along the route.

Co-Learning Knowledge is shared between local people and 'outsiders'. New understandings and plans to address issues are created together. 'Outsiders' facilitate this colearning (Waterman et al. 2001).

As stated previously, co-learning was evident in the 'Wheeling Walks' (Reger-Nash et al. 2003) and the 'The Stanford Healthy Neighborhood Tool' (Buman et al. 2013) studies, as data gathered in both studies informed the participants' understanding of the relevant local issues, leading to the development of potential solutions. There was also development in the 'SMILE' programme (Hickey et al. 1996) as some of the participants took over leading sections of the sessions, thus entering a co-learning phase. 
In the 'Triangle Ystradgynlais Fitness 50+' project (Davies et al. 2008), participants formed a management committee four weeks into the intervention. Class content was amended following feedback from participants, which meant that co-learning was taking place. Two evaluation events were held after two and four years. Since the social element of attending the exercise classes was important to participants, the management committee expanded this element, establishing trips, walks and healthy lunches.

Collaboration There is equal involvement from all partners in the research process, to combine knowledge and plans to improve a situation (Minkler and Wallerstein 2008).

The Sullivan-Marx et al. (2011) study concerned the recruitment and retention strategies that were employed to encourage older adults to attend an exercise class: 'Exercise for LIFE'. The study was initiated by a Council of Elders (management committee), whose members were interested in developing a research study that would increase understanding of the health benefits of exercise. The Council of Elders worked with researchers to design and promote the study, advising on scheduling, eligibility, flyer design and face-to-face methods of recruitment. The Council of Elders' involvement at all stages meant that it was valued as a member-driven programme. This study demonstrates genuine collaboration, with colearning also evident as they gained knowledge about uptake and adherence to an exercise intervention.

'Research circles' were developed in the final stage of the 'Let's go for a walk!' study (Ståhl et al. 2008). These were set up and led by researchers, involving eight older adults and eight local stakeholders. The members of the 'research circles' reviewed evidence gathered and worked collaboratively to develop a strategy to improve the local environment, increasing accessibility, making it easier for the local population to be physically active.

Peer Leadership Older adults, sharing the characteristics of the target group, trained to deliver specific interventions and act in a specific role (Simoni et al. 2011).

The final stage of the Hickey et al. (1996) study, 'SMILE', involved training peer leaders. The research team, senior centre staff, and participants themselves, selected the peer leaders after six weeks' involvement in the study. Other participants were selected to act as facilitators, to prepare the room and serve refreshments. From 12 weeks, the peer leaders and facilitators ran the sessions. Peer leaders were trained to provide encouragement and positive reinforcement to participants, developing a belief in the benefits of exercise.

Peer leadership was an outcome of the 'Triangle Ystradgynlais Fitness 50+' project (Davies et al. 2008). Participants took over the running of the class six weeks after the pilot phase had begun. Sustainability was the focus of the follow-up work on the 'PRAISEDD' ('People Reducing Risk and Improving Strength Through Exercise, Diet and Drug Adherence') project (Michael et al. 2012). An advanced practice nurse and an exercise trainer had led the 12-week, thrice weekly, pilot of hour-long group exercises. A 'champion' participant was identified who could lead the classes after the pilot phase. The research team provided training, class materials, and support for two years. Classes were delivered by the champion, a peer-leader, once or twice per week throughout this time. 
Mentoring Older adults, sharing the same characteristics as the target group, share information, attempt to influence knowledge, attitudes or behaviour (Peel and Warburton 2009).

The 'Active Adult Mentoring Program' (Buman et al. 2011) recruited seven peer volunteer mentors. In the active intervention arm, peer mentors delivered weekly sessions, establishing a social support network, building trust and rapport and supporting individual participants to learn skills to initiate and maintain physical activities. In the standard community intervention arm, the peer mentors delivered two basic health education sessions after receiving training from the programme staff. They provided praise and reinforcement, but individual plans were not developed.

Whilst older adults played key roles in each of the included studies, in all but one case they were contributing to interventions that had already been designed by researchers. Even in cases where older adults were consulted and involved at an early stage, the initial idea for the intervention, or the realisation that an intervention was required, was researcher led.

\section{Objective Two: Recorded Benefits of Involving Older Adults}

Whilst none of the studies reported specifically on the benefits of involving older adults, they did report on PA adherence and engagement (Table 5). All four of the studies describing peer leadership or mentoring reported that participants continued to engage in activity sessions at longer-term follow-up stages. All of these interventions were sustained beyond the study period. Similarly, the Sullivan-Marx et al. (2011) intervention, using a collaborative approach, was sustained as a permanent programme following the study period. It was reported that the close working relationship between the Council of Elders and researchers meant that barriers were addressed quickly with solutions implemented. Studies reporting on the amount of PA undertaken all demonstrated increases. For the Buman et al. (2011) programme, results suggest that the encouragement and skills taught by the peer mentors may have had a positive effect on long-term adherence, if not on uptake, with Exercise Motivation Scale scores significantly higher for the active intervention arm at both 16 weeks and 18 months. Likewise, Hooker et al. report significant positive changes for MVPA, overall PA, selfefficacy for PA, social support, self-regulation, functional and aerobic fitness. There was also high attendance over the 16 sessions and high compliance with completing and submitting weekly logs. Satisfaction with the programme was very high, suggesting that the incorporation of findings from the formative research (consultation) with this population could have been an influencing factor.

Reger-Nash et al. (2003) report a 32\% increase in walking in Wheeling, compared to $18 \%$ in the comparison community. Those participants who were least active at baseline made significant increases that were maintained at six and 12 months. The success of the campaign, with messages developed and tested in consultation with older adults, was supported by increases in feelings of empowerment amongst the Community Advisory Board members, who had planned, implemented and promoted the intervention.

Studies that focussed on identifying environmental barriers (Buman et al. 2013; Ståhl et al. 2008), (consultation, cooperation, co-learning and collaboration) achieved 


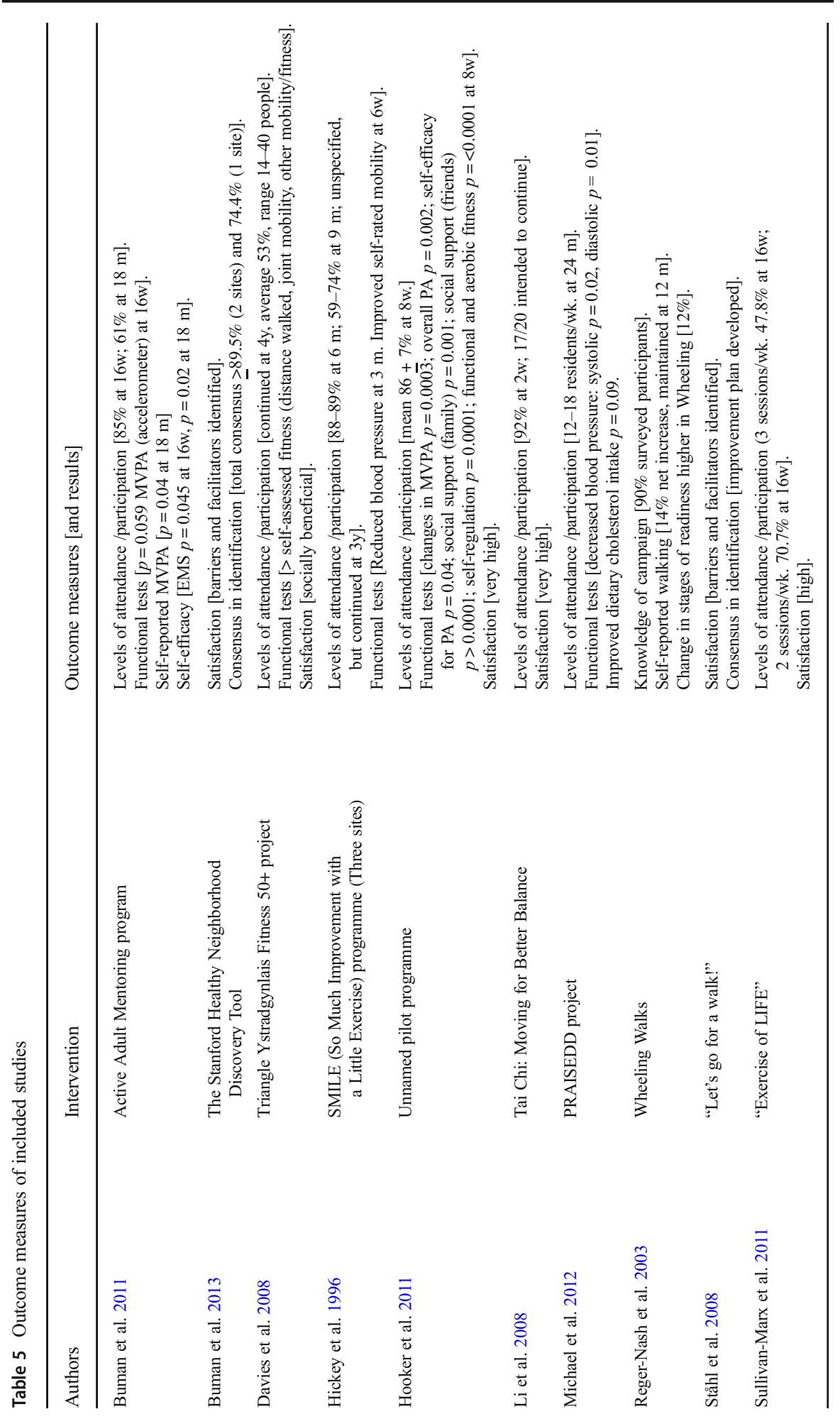


consensus on prioritising issues to be addressed. Involving older adults in the iterative process to identify barriers and facilitators to active living appeared to produce practical solutions with high levels of consensus.

The Li et al. 2008) programme had high levels of attendance at the pilot class (92\%) with no dropouts. Satisfaction was very high, with all participants indicating that they would continue to attend a community class. There was no long-term follow-up to this study, so it is not possible to consider long-term adherence. The videotape and guidebook were well received by participants, with 14 out of 20 participants reporting that they were using them at home three weeks after the intervention had finished. Whilst it was not specifically reported as a success factor, the involvement of older adults in the iterative development (consultation) may have created a more appealing programme.

In each of these studies, in their different contexts, positive results have been reported for adherence; levels of PA, sustained delivery of activity sessions; practical solutions to environmental barriers to PA; and high satisfaction with a developed programme. However, the extent to which these results were due to the involvement of older adults is not made clear in any of the studies.

\section{Discussion}

The purpose of this review was to (i) identify how older adults have been involved in the design, delivery, implementation and promotion of interventions to promote PA amongst their age group, and (ii) identify the recorded benefits of such an approach. As demonstrated in Table 2, we identified ten papers that met the inclusion criteria. Of these, six were given the highest possible rating according to the relevant assessment criteria. Four of the papers were assessed as being of moderate quality. Three of these four moderate papers were reporting participatory studies, meaning that they were assessed against the criteria in Waterman et al. (2001). These criteria are extensive, covering 20 questions, with 63 sub-questions. It is difficult to report on all these criteria given the word limitations for journal articles. Some of the quality areas may not be reported on, according to the focus of the paper written for a specific journal. For example, a paper reporting on the design of an intervention may not report on data collection and analysis methods, thereby reducing the scoring on the quality assessment. Scores of moderate quality in these reported studies do not, then, necessarily indicate a poorer quality research study, but rather a limitation in the number of areas of participatory research reported. Within this review, we have included high quality evidence to understand the state of older adults' involvement and on which to base any recommendations.

Six types of involvement of older adults are evident: (i) consultation; (ii) cooperation; (iii) co-learning; (iv) collaboration (v) peer leadership and (vi) mentoring. Four studies involved older adults in the design and promotion phases of an intervention, where they provided focus on how to promote the intervention to maximise uptake. Two studies involved older adults in the delivery and development of interventions, through data collection to identify target areas for change and improvement in their local neighbourhoods. Three studies involved older adults in the design of interventions through contribution to content. Four studies involved older adults in 
the delivery and implementation of interventions as peer leaders or mentors. The types of involvement of the included studies are summarised in Table 4. None of the studies in this review included more than three different types of involvement.

Whilst all of the studies reported positive relationships between older adults' involvement and increased levels of satisfaction, participation, or measures of physical health, it is difficult to identify the reason for success. Public health interventions are often complex, multi-level interventions that take place in particular settings and it can be difficult to reach definitive conclusions about their effects (Pawson et al. 2005). This limitation was reported in Buman et al. (2011) as the authors were unable to conclude whether the success of the 'Active Adult Mentoring Program' was the result of peer mentoring alone, or due to goal setting, mental imagery and problem solving exercises, or a combination of all of those elements. Similarly, Hooker et al. (2011) report being unable to know which elements of the intervention were most important and effective. The 'Active Adult Mentoring Program' (Buman et al. 2011) and 'Wheeling Walks' (Reger-Nash et al. 2003) were the only interventions with comparisons or controls, yet the specific success factors were still difficult for authors to isolate. The lack of demographic detail about the peer mentors, and the older adults involved in the planning stages of the 'Wheeling Walks' study, means that conclusions about the influence of personal characteristics cannot be drawn. There is good evidence of the importance and influence of trainers and leaders in exercise classes (Estabrooks et al. 2004; Hawley-Hague et al. 2014) yet we are unable to examine the extent to which the personalities and characteristics of the peer mentors, leaders and planners in these studies influenced uptake and adherence within the studies.

The lack of specific tracking and reporting of the benefits of involving older adults in the included studies highlights one of the challenges of carrying out participatory research. Including participants as equals in the research process, following a process of planning, acting, observing and reflecting in order to effect change (Meyer 1993) takes time, knowledge and resources which organisations and policy makers may not have. Participatory research methodologies demand systematic, regular critical reflection on actions taken and their relationship to the outcomes achieved (Kemmis and McTaggart 1988). It is, arguably, quicker to conduct and implement research and ideas that have been developed without the involvement of the people it is aimed to affect. This presents a challenge to researchers, research funders, commissioners, policy makers and organisations promoting PA amongst older adults. To develop interventions with the target group, in order to maximise the opportunities for engagement, will require adequate resources in terms of both time and funding. The benefits of investing in this approach include the development of interventions that are appropriate for the local population, feasible to deliver and can lead to sustainable change. Those involved in developing the interventions, through participatory approaches, can feel ownership of the changes and can facilitate rapid uptake (Waterman et al. 2001).

\section{Limitations of the Review}

Only studies in English were included in this review. They are largely exploratory and descriptive in nature, making it difficult to assert definitive conclusions. The included studies' authors, whilst reporting positive findings, have highlighted that findings are difficult to generalise beyond the specific study context. Realist review recognises this 
difficulty and resists the temptation to present definitive conclusions and generalisations from complex interventions within communities. Instead, what appears to work as a result of carrying out various actions in particular situations is presented (Pawson et al. 2005).

\section{Recommendations}

Given the difficulty for the studies included in this review to demonstrate a clear link between the outcomes of their interventions and the involvement of older adults, specific consideration should be given in future studies to reporting the exact nature of involvement, together with clear measures of impact. In line with the principles of realist review (Pawson et al. 2005), it would be beneficial for researchers to track the different elements of a study, to identify what works, for whom, in which circumstances. It would then be possible to identify what benefits are gained through involving older adults. Whilst the specific benefits of involving older adults were unreported in the included studies, the nature of involvement in the interventions has been described in enough detail for similar studies to be developed. Further research in each of these areas would assist in the identification of the factors that influence engagement in PA. The studies that took place in senior centres could be replicated in other such centres; the studies that focussed on sub-groups of older adults from low income areas, or of African American origin, could be implemented with similar or modified cohorts and with appropriate cultural tailoring; the assessment studies that took place in local neighbourhoods could be replicated in other districts. This further research should include recognition of the context within which the research is undertaken, along with tracking of the benefits of involvement, to reflect on the influence of older adults' involvement. Conducting participatory research to address challenges faced in communities, such as low levels of physical activity, would involve reflection on action and outcomes, thus enabling the impact of involvement to be identified.

The sustainability of interventions to promote PA is of great interest to clinicians, commissioners and policy makers. With the ever-increasing demand for health and social care services, policy makers are looking outside of traditional models of service provision to see where communities can provide support for their own members. The apparent mid to long-term sustainability of the peer-led and mentoring programmes in this review indicates that such models could be attractive to address national and local challenges. Encouraging participants to take on responsibility in the early stages of the delivery of an exercise or activity class, and stating that this would be a crucial element of sustainability, could be replicated in future interventions. Recruiting older adult volunteers to public health campaigns would provide clinicians and policy makers with an excellent resource. Involving older adults in structured observations and assessments of their local neighbourhoods would also be a useful, cost effective resource, enabling large areas to be assessed by volunteers. Clinicians, commissioners and policy makers can benefit from these findings by involving local older adults in their areas to design, develop, implement and promote PA interventions that focus on what is important to them locally. Genuine participation should be the goal for those tasked with addressing the needs of local communities, in order to meet the challenge of increasing PA within the contexts of where older adults live and work. 


\section{Conclusions}

This review has identified ten papers where older adults have been involved in the design, delivery, implementation and promotion of PA interventions. Positive outcomes were achieved in all studies, although the reasons for success are difficult to discern. Although the findings are limited, they suggest that there is some value in the involvement of older adults at various levels of intervention development. This is in line with the participatory research conducted in other fields of public health. Public health practitioners and researchers should consider how they might engage and involve older adults in developing PA interventions. Specifically, future research needs to focus on clarifying the nature of involvement; recognising the influence of that involvement; the context within which it occurs; and how the outcomes of the interventions are described and measured.

Acknowledgements The work was supported by the first author as part of a self-funded PhD programme.

Many thanks go to the older adults in my personal and professional life who have inspired and encouraged me to promote physical activity. Thanks also go to my husband for providing wise words, emotional, moral and financial support, enabling me to conduct this $\mathrm{PhD}$ research.

\section{Compliance with Ethical Standards}

Conflict of Interest The authors declare that they have no conflict of interest.

Open Access This article is distributed under the terms of the Creative Commons Attribution 4.0 International License (http://creativecommons.org/licenses/by/4.0/), which permits unrestricted use, distribution, and reproduction in any medium, provided you give appropriate credit to the original author(s) and the source, provide a link to the Creative Commons license, and indicate if changes were made.

\section{References}

Angevaren, M., Aufdemkampe, G., Verhaar, H. J., Aleman, A., \& Vaanhees, L. (2008). Physical activity and enhanced fitness to improve cognitive function in older people without known cognitive impairment. Cochrane Database of Systematic Reviews, (16, 2), CD005381. https://doi.org/10.1002/14651858. CD005381.pub3.

Buman, M., Giacobbi, P., Jr., Dzierzewski, J., et al. (2011). Peer volunteers improve long-term maintenance of physical activity with older adults: A randomized controlled trial. Journal of Physical Activity \& Health, 8(Suppl 2), S257-S266.

Buman, M. P., Winter, S. J., Sheats, J. L., Hekler, E. B., Otten, J. J., Grieco, L. A., \& King, A. C. (2013). The Stanford healthy neighborhood discovery tool. A computerized tool to assess active living environments. American Journal of Preventive Medicine, 44(4), e41-e47. https://doi.org/10.1016/j.amepre.2012.11.028.

Burroughs, E., Rheaume, C., Feeney, S. et al. (2009). Recruiting African American Men: What Works. Hilton Head Island, SC: American Academy of Health Behavior, Annual Meeting, 2009.

Burroughs, E., Hooker, S. P., Wilcox, S., et al. (2009a). Development of a tailored physical activity intervention for middle-aged and older African American men. In Annual meeting (p. 2009). Philadelphia, PA: American Public Health Association.

Cavill, N., Kahlmeier, S., \& Racioppi, F. (2006). Physical activity and health in Europe: Evidence for action. Copenhagen: World Health Organization. 
Centre for Reviews and Dissemination (2008). Systematic reviews: CRD's guidance for undertaking reviews in healthcare. York: University of York. Available from: www.york.ac.uk/inst/crd/, accessed 8 September 2017. ISBN 978-1-900640-47-3.

Centres for Disease Control and Prevention (2015). How much physical activity do older adults need? Available at: http://www.cdc.gov/physicalactivity/everyone/guidelines/olderadults.html, accessed 8 September 2017.

Chief Medical Officers (2011). Start Active Stay Active. London: Department of Health.

CLES Consulting and the New Economics Foundation (2010). Big Lottery Fund National Well-being Evaluation: Year 1 Report.

Davies, J., Lester, C., O'Neill, M., \& Williams, G. (2008). Sustainable participation in regular exercise amongst older people: Developing an action research approach. Health Education Journal, 67(1), 4555. https://doi.org/10.1177/0017896907086157.

Department of Health. (2004). At least five a week: Evidence on the impact of physical activity and its relation to health. London: Department of Health.

Department of Health. (2005). Delivering choosing health: Making healthier choices easier. London: Department of Health.

Department of Health. (2009). On the state of public health. In Annual report of the chief medical officer. London: Department of Health.

Department of Health (2010). Practical approaches to co-production. London: HM government, Department of Health.

Department of Health (2012). A short guide to health and wellbeing boards. Available: http://healthandcare.dh. gov.uk/hwb-guide/; accessed 8 September 2017.

Effective Public Health Practice Project (2007). Quality assessment tool for quantitative studies. Available at: www.ephpp.ca/tools.html accessed 8 September 2017.

Estabrooks, P. A., Munroe, K. J., Fox, E. H., Gyurcsik, N. C., Hill, J. L., Lyon, R., Rosenkranz, S., \& Shannon, V. R. (2004). Leadership in physical activity groups for older adults: A qualitative analysis. Journal of Aging and Physical Activity, 12(3), 232-245.

Falkingham, J., Evandrou, M., McGowan, T., Bell, D. \& Bowes, A. (2010). Demographic issues, projections and trends: older people with high support needs in the UK. Report for the Joseph Rowntree Foundation. Southampton: ESRC Centre for Population Change, University of Southampton and University of Stirling and Joseph Rowntree Foundation.

Frosch, D. L., Rincon, D., Ochoa, S., \& Mangione, C. M. (2010). Activating seniors to improve chronic disease care: Results from a pilot intervention study. Journal of the American Geriatrics Society, 58(8), 1496-1503. https://doi.org/10.1111/j.1532-5415.2010.02980.x.

Hawley-Hague, H., Horne, M., Skelton, D. A., \& Todd, C. (2014). Older adults' uptake and adherence to exercise classes: Instructors' perspectives. Journal of Aging and Physical Activity, 24(1), 119-128. https://doi.org/10.1123/japa.2014-0108.

Health Direct Australia (2016). Physical activity guidelines for older adults. Available at: https://www. healthdirect.gov.au/physical-activity-guidelines-for-older-adults, Accessed 21 Jun 2019.

Herr, K., \& Anderson, G. L. (2005). The action research dissertation. Thousand Oaks, California: Sage ISBN0-7619-2991-6.

Hibbard, J.H. \& Greene, J. (2013). What the evidence shows about patient activation; better health outcomes and care experiences; fewer data on costs. Health Affairs, 32:2207-214. https://doi.org/10.1377 /hlthaff.2012.1061, 207.

Hickey, T., Sharpe, P.A., Wolf, F.M., Robins, L.S., Wagner, M.B. \& Harik, W. (1996). Exercise participation in a frail elderly population. Journal of Health Care for the Poor and Undeserved 7 (3):219-231. ISSN: 1049-2089 ; E-ISSN: 1548-6869.

Hillsdon, M., White, I., \& Foster, C. (2002). Advising people to take more exercise is ineffective: A randomized controlled trial of physical activity promotion in primary care. International Journal of Epidemiology, 31, 808-815.

Hooker, S. P., Harmon, B., Burroughs, E. L., Rheaume, C. E., \& Wilcox, S. (2011). Exploring the feasibility of a physical activity intervention for midlife African American men. Health Education Research, 26(4), 732-738. https://doi.org/10.1093/her/cyr034.

Horne, M., Skelton, D., Speed, S., \& Todd, C. (2010). The influence of primary health care professionals in encouraging exercise and physical activity uptake among White and south Asian older adults: Experiences of young older adults. Patient Education and Counselling, 78, 97-103. https://oi. org/10.1016/j.pec.2009.04.004.

Kemmis, S., \& McTaggart, R. (Eds.). (1988). The action research planner (3 ${ }^{\text {rd }}$ edition). Geelong: Deakin. University Press. 
Kmet, L.M., Lee, R.C., Cook, L.S. (2004). Standard quality assessment criteria for evaluating primary research papers from a variety of fields. Health Technology Assessment Initiative 13, Alberta Heritage Foundation for Medical Research.

Li, F., Harmer, P., Mack, K. A., Sleet, D., Fisher, K. J., Kohn, M. A., Millet, L. M., Xu, J., Yang, T., Sutton, B., \& Tompkins, Y. (2008). Tai chi: Moving for better balance - development of a community-based falls prevention Programme. Journal of Physical Activity and Health, 5(3), 445-455.

Lorig, K., \& Alvarez, S. (2011). Re: Community based diabetes education for Latinos. Diabetes Education, 37(1), 128. https://doi.org/10.1177/0145721710393089.

Meyer, J. (1993). New paradigm research in practice: The trials and tribulations of action research. $B M J$, 320(7728), 178-181.

Michael, K. M., Shaughnessy, M., \& Resnick, B. (2012). People reducing risk and improving strength through exercise, diet and drug adherence (PRAISEDD): A case report on long-term site adoption. Translational Behavioral Medicine, 2(2), 236-240. https://doi.org/10.1007/s13142-012-0127-6.

Ministry of Health. (2013). Guidelines on physical activity for older people (aged 65 years and over). Wellington: Ministry of Health.

Minkler, M., \& Wallerstein, N. (Eds.). (2008). Community based participatory research for health: From process to outcomes. San Francisco: Jossey Bass.

Minkler, M., Wallerstein, N., Wilson, N. (2008). Improving health through community organization and community building. In: Glanz, K., Rimer, B.K., Viswanath, K. (eds.) Health Behaviour and Health Education: Theory Research and Practice $4^{\text {th }}$ Edition; San Francisco: Jossey-Bass, p:287-312. ISBN: 978-0-470-39629-2.

Morgan, O. (2005). Approaches to increase physical activity: Reviewing the evidence for exercise referral schemes. Public Health, 119, 361-370. https://doi.org/10.1016/j.puhe.2004.06.008.

NHS Choices (2015). Physical activity guidelines for older adults. Available at: http://www.nhs. uk/Livewell/fitness/Pages/physical-activity-guidelines-for-older-adults.aspx, accessed 8 September 2017.

NHS England (2013). Transforming participation in health and care: 'The NHS belongs to us all'. Patients and Information Directorate, NHS England. Available at: http://www.england.nhs.uk/wpcontent/uploads/2013/09/trans-part-hc-guid1.pdf, accessed 8 September 2017.

Parchman, M. L., Zeber, J. E., \& Palmer, R. F. (2010). Participatory decision making, patient activation, medication adherence, and intermediate clinical outcomes in type 2 diabetes: A STARNet study. Annals of Family Medicine, 8(5), 410-417. https://doi.org/10.1370/afm.1161.

Pawson, R., Greenhalgh, T., Harvey, G., \& Walshe, K. (2005). Realist review - a new method of systematic review designed for complex policy interventions. Journal of Health Services Research \& Policy, 10(Suppl 1), 21-34. https://doi.org/10.1258/1355819054308530.

Popay, J., Rogers, A., Williams, G. (1998). Rationale and standards for systematic review of qualitative literature in health services. Qualitative Health Research, 8(3): 341-351.

Nancye M Peel and Jeni Warburton, Using senior volunteers as peer educators: What is the evidence of effectiveness in falls prevention? Australasian Journal on Ageing, Vol 28 No 1 March 2009, 7-11.

Ramsden, V. R., McKay, S., \& Crowe, J. (2010). The pursuit of excellence: Engaging the community in participatory health research. Global Health Promotion, 17(4), 32-42.

Reger-Nash, B., Simon, K. J., Cooper, L., \& Bauman, A. (2003). Wheeling walks: A media-based intervention to increase walking. In Health, equity and environment. The fourth international conference on walking in the 21st century proceedings (pp. 313-324).

Scottish Intercollegiate Guidelines Network (SIGN) (2008). SIGN 50: A Guideline Developer's Handbook. Available at: http://www.sign.ac.uk/guidelines/fulltext/50/index.html, accessed 8 September 2017.

Simoni, J. M., Franks, J. C., Lehavot, K., \& Yard, S. S. (2011). Peer interventions to promote health: Conceptual considerations. The American Journal of Orthopsychiatry, 81(3), 351-359.

Sport England. (2007). Active design: Promoting opportunities for sport and physical activity through good design. London: Sport England.

Ståhl, A., Carlsson, G., Hovbrandt, P., \& Iwarsson, S. (2008). “Let’s go for a walk!": Identification and prioritisation of accessibility and safety measures involving elderly people in a residential area. European Journal of Ageing, 5(3), 265-273. https://doi.org/10.1007/s10433-008-0091-7.

Stewart, A. L., Verboncoeur, C. J., McLellan, B. Y., et al. (2001). Physical activity outcomes of CHAMPS II: A physical activity promotion program for older adults. Journals of Gerontology Series A: Biological Sciences and Medical Sciences, 56, 465-470. ISSN: 1079-5006 ; PMID: 11487597 Version:1.

Sullivan-Marx, E. M., Mangione, K. K., Ackerson, T., Sidorov, I., Maislin, G., Volpe, S. L., \& Craik, R. (2011). Recruitment and retention strategies among older African American women enrolled in an exercise study at a PACE program. The Gerontologist, 51(Suppl 1), S73-S81. https://doi.org/10.1093 /geront/gnr001. 
von Elm, E., Altman, D. G., Egger, M., Pocock, S. J., Gøtzsche, P. C., \& Vandenbroucke, J. P. S. T. R. O. B. E. I. (2008). The strengthening the reporting of observational studies in epidemiology (STROBE) statement: Guidelines for reporting observational studies. Journal of Clinical Epidemiology, 61(4), 344-349. https://doi.org/10.1016/j.jclinepi.2007.11.008.

Waterman, H., Tillen, D., Dickson, R., \& de Koning, K. (2001). Action research: A systematic review and guidance for assessment. Health Technology Assessment, 5(23) ISSN: 1366-5278 ; PMID: 11785749 Version:1.

World Health Organization. (2010). Global recommendations on physical activity for health. Geneva: World Health Organization. ISBN, 9789241599979.

World Health Organization (2015). Physical activity and older adults. Available at: http://www.who. int/dietphysicalactivity/factsheet_olderadults/en/, accessed 8 September 2017.

Publisher's Note Springer Nature remains neutral with regard to jurisdictional claims in published maps and institutional affiliations.

\section{Affiliations}

\section{Elisabeth R Boulton ${ }^{1,2}$ - Maria Horne ${ }^{3}$. Chris Todd ${ }^{1,2,4}$}

1 Division of Nursing, Midwifery and Social Work, School of Health Sciences, Faculty of Biology, Medicine and Health, University of Manchester, Jean McFarlane Building, University Place, Oxford Road, Manchester M13 9PL, UK

2 Manchester Academic Health Science Centre, Manchester, UK

3 School of Healthcare Faculty of Medicine and Health, University of Leeds, Leeds, UK

4 Manchester University NHS Foundation Trust, Manchester, UK 